\title{
LINGUAGEM E FORMAÇÃO NA TEORIA DA CONSCIÊNCIA DO JOVEM HEGEL
}

Erick C. de Lima ${ }^{1}$

RESUMO: O trabalho pretende expor, em suas linhas gerais, a ligação, presente na teoria da consciência desenvolvida por Hegel, na Filosofia do Espírito de Jena, entre a formação da consciência, compreendida no bojo dos processos de individualização e desenvolvimento das capacidades práticocognitivas, e a pré-articulação linguística da cognição. Para isso, o ponto de partida é a exposição dos aspectos gerais da teoria hegeliana da consciência, nessa fase. Em seguida, interpreta-se essa teoria da consciência, relacionando-a a processos societários de desenvolvimento de capacidades prático-cognitivas. A partir disso, procura-se então delinear os aspectos fundamentais da relação entre razão teórica e linguagem. Finalmente, discute-se a recuperação da consideração sobre a linguagem, no processo de formação da consciência.

PALAVRAS-CHAVE: Formação. Linguagem. Consciência. Cognição. G. W. F. Hegel.

\section{Consciência e seu outro}

Hegel chega, por volta de 1802, ao princípio fundamental a ser operacionalizado na sua teoria da consciência: a inteligência, cuja essência é, enquanto conceito absoluto, poder passar ao contrário imediato de si. Justamente a pormenorização, para a própria consciência individual, do processo pelo qual ela passa da singularidade à universalidade, isto é, vê sua

\footnotetext{
${ }^{1}$ Mestre e Doutor em Filosofia pela Universidade Estadual de Campinas (UNICAMP), com PósDoutorado pela mesma universidade. Atualmente, é Professor doutor (adjunto) no Departamento de Filosofia da Universidade de Brasília (UnB), onde também participa do Programa de Pós-Graduação em Filosofia (PPG-FIL/UnB). E_mail: ericklima2006@yahoo.com.br
} 
singularidade sendo gradativamente suspensa até desembocar no vínculo comunitário com outras consciências singulares, é a intuição fundamental do vínculo que Hegel pretende estabelecer entre teoria do reconhecimento e teoria da consciência (SIEP, 1976, p. 180)². É verdade que os elementos exteriores desse processo de uma "socialização individualizante" - ou seja, da mediação intersubjetiva da formação de capacidades prático-cognitivas individuais - já se tornam claros no System der Sittlichkeit, uma vez que um significado concreto da singularidade individual sempre se vinculara a formas societárias de existência, ainda em um nível pré-estatal (HONNETH, 1992). Fazendo da consciência o elemento no qual o espírito se desenvolve (LIMA, 2008e), em direção ao autoconhecimento absoluto, enquanto reabsorção da ideia que se exteriorizou na filosofia da natureza, o Systementwurf 1803/04 promove, prenunciando o sistema maduro, a inserção do desenvolvimento da eticidade em uma filosofia do espírito. Na medida em que "[...] faz preceder à filosofia prática, compreendida enquanto filosofia da eticidade, uma derivação de seu objeto no âmbito da teoria da consciência, uma derivação que não é já componente do sistema da eticidade" (SCHNÄDELBACH, 2000, p. 139), Hegel acaba por tornar prescindível a pressuposição do télos do desenvolvimento da eticidade e a consequente exterioridade do método de reconstrução desse movimento (LIMA, 2006, p. 120).

Sem dúvida, um importante marco da inserção da filosofia prática na filosofia do espírito pela via do conceito de consciência (KIMMERLE, 1970, p. 256) se encontra nos fragmentos 15 a 17 da Filosofia do Espírito de 1803/ 04. Consciência e espírito estão em uma relação interna de mútua determinação: a consciência é "apenas" o conceito da identidade da unidade e da infinitude, o qual somente na infinitude do espírito é "para si", unidade absoluta dos contrapostos (HEGEL, 1986, p. 183-184). Em tais fragmentos "a essência da consciência é [...]", "a primeira forma da existência do espírito é a consciência em geral [...]" e "é somente a forma [...]" -, nos quais Hegel promove suas primeiras considerações sistemáticas sobre o conceito de consciência, são desenvolvidas caracterizações gerais que se deixam conduzir ao princípio básico de que os dois "lados" da consciência, das Bewusstseiende e das, dessen es sich bewusst ist, são imediatamente um e, por isso, constituem a forma da universalidade.

\footnotetext{
${ }^{2}$ Comparando com sua posição delineada em 1968, Habermas deixa ainda mais claro como espera vincular a questão da mediação entre sujeito e objeto, e o duplo processo de uma "individualização pela socialização" (HABERMAS, 1988). Habermas já havia sustentado isso, ao mencionar o vínculo entre a constituição do eu e a conexão entre os media. "Porque Hegel não vincula a constituição do eu à reflexão do eu solitário sobre si mesmo, mas a compreende a partir de processos de formação - a saber, de concordância comunicativa de sujeitos contrapostos - não é reflexão como tal que é decisiva, mas o medium no qual a identidade do universal e do singular se estabelece" (HABERMAS, 1974, p. 796).
} 


\begin{abstract}
A essência (das Wesen) da consciência é que ela seja imediatamente [...] unidade absoluta da oposição. Ela somente pode ser isso ao ser ela mesma, imediatamente, na medida em que ela é contraposta, ambos os membros da oposição, sendo neles simplesmente, enquanto membros da oposição, imediatamente o contrário de si mesma, a diferença absoluta, a diferença que se suspende a si mesma e que é suspensa. Nesta unidade da oposição, o que é consciente (das Bewußtseiende) é um dos lados da mesma; e aquilo de que se é consciente (das, dessen es sich bewußt ist), o outro lado. Ambos são essencialmente o mesmo, ambos [são] uma unidade imediata da singularidade e da universalidade. (HEGEL, 1986, p. 189).
\end{abstract}

A assimilação hegeliana da teoria da consciência é, assim, a transformação da mesma numa investigação da unidade substancial e previamente articulada da consciência e daquilo de que se é consciente, isto é, como autoconsciência. Com efeito, tal compreensão, que antecipa quase textualmente o início do segundo tomo da Fenomenologia do Espírito, se pauta pela unidade dialética de consciência e autoconsciência, ainda em sua forma imediata (WILDT, 1983, p. 330).

A consciência é, enquanto o que é consciente de si mesmo a partir de si enquanto consciência, a identidade ativa e negante (die tätige negierende Identität), a qual retorna a si a partir do seu tornar-seconsciente de um outro que não ela mesma, e suprime este outro através do passar a este outro. (HEGEL, 1986, p. 189).

Enquanto unidade imediata de universalidade e singularidade, da indeterminidade enquanto totalidade e da determinidade - e também sua contraposição imediatamente suspensa -, a consciência é tanto consciência do objeto, como consciência de si mesma como consciente do objeto (suspensão da primeira contraposição), como ainda o movimento de passagem (e de suspensão da contraposição) entre consciência e autoconsciência ${ }^{3}$. Entretanto, ainda que sua essência seja "[...] igualmente o ser-suspenso de ambos" (HEGEL, 1986, p. 189), a consciência aparece, imediatamente, como um de seus lados, "[...] o qual é ele mesmo determinado como o ativo (als Tätiges) e, por isso, como o que suspende (als Aufhebendes)" (HEGEL, 1986, p. 189); e, nesse sentido, como algo que não "[...] põe a si mesmo somente como consciência, não como aquilo de que se é consciente,

\footnotetext{
${ }^{3}$ Tal processo Habermas vê prosseguir em Humboldt, Pierce, Dilthey, Cassirer, Heidegger e Wittgenstein Expoentes mais recentes de um paradigma epistemológico vinculado ao cartesianismo da autorreflexão seriam Husserl, Sartre e, mais recentemente, também Roderick Chrisholm e Dieter Henrich.
} 
e é, portanto, consciência somente singular, formal, negativa, e não absoluta. Pois aquilo de que é consciente ela não põe como igual a si" (HEGEL, 1986, p. 189). Na medida em que a consciência se põe somente como o primeiro lado, a forma do consciente, é determinada pelo exterior, sendo por isso "empírica". "Esta consciência empírica tem, todavia, de ser consciência absoluta, ou imediatamente o outro que não o que ela é, tem de ter em si mesma seu ser-outro (sein Anderssein), sua igualdade positiva com a consciência" (HEGEL, 1986, p. 189-190).

Télos e desdobramento do espírito se estabelecem: trata-se da suspensão absoluta da contraposição ínsita à consciência em direção à posição de si no ser-outro. Ao contrário do que se dá no System der Sittlichkeit e no Naturrechtsaufsatz, a unidade ética do povo é tratada aqui como um objeto a ser construído através de um desenvolvimento vinculado à teoria da consciência.

Ele existe como objeto (Gegenstand) de sua consciência singular, enquanto um exterior, no qual eles, tal como são nele absolutamente um, se desligam (sich abscheiden) e são para si. É a unidade universal e o meio absoluto (absolute Mitte) da mesma, e onde eles estão postos idealmente, enquanto suspensos; e este seu estar-suspenso (dies ihr Aufgehobensein) é, ao mesmo tempo, para eles mesmos. (HEGEL, 1986, p. 188).

Neste sentido, o movimento que define a filosofia do espírito - e, com ela, também a filosofia prática ${ }^{4}$ - no Systementwurf 1803/04 é o movimento pelo qual a consciência vai paulatinamente apreendendo aquilo de que é consciente como sendo ela mesma, reconhecendo a unidade entre consciência de si e consciência como meio absoluto da mesma, tornandose, ao término do movimento, realidade absoluta da consciência, o contrário do que ela imediatamente é.

Este é o fim, a realidade absoluta da consciência, à qual nós temos de elevar seu conceito. É a totalidade que ela tem enquanto espírito de um povo, o qual é absolutamente a consciência de todos, que eles intuem (anschauen) e que contrapõem a si enquanto consciência, mas do mesmo modo conhecem imediatamente sua contraposição, sua singularidade como individualidade nele suspensa, ou sua consciência como um absolutamente universal. (HEGEL, 1986, p. 190).

\footnotetext{
4 "a linguagem, o instrumento e os bens-de-família não são simplesmente um dos lados da oposição que se contrapõe ao que se põe como consciente, e sim são da mesma forma relacionados a ele; [são] o meio, aquilo em que ele se separa de sua oposição verdadeira - na linguagem, [separa-se] de outros aos quais ele fala; no instrumento, daquilo contra o qual ele exerce com o instrumento sua atividade; através dos bens-de-família, dos membros da sua família." (HEGEL, 1986, p. 193).
} 
O desenvolvimento do espírito desde a sua célula - a consciência, não como a "autoconsciência pura" do idealismo subjetivo, mas como unidade imediata da universalidade e singularidade -, coincide com o movimento de autossuspensão da singularidade, um processo cujas características propriamente filosófico-sociais e epistemológicas, o descentramento da perspectiva individualista da singularidade excludente e a articulação linguística prévia da cognição, serão amplamente realçados pela teoria do reconhecimento. Somente no povo, ao ser suspensa como singular, a atividade consciente adquire existência duradoura, tornando-se universalidade de uma obra comum, tanto de um ponto de vista ético-político quanto cognitivo.

[...] como lá [em seu contrário E.C.L] o conceito absoluto da consciência existe como singularidade absoluta, [ele tem] aqui de existir como conceito determinado, ou como em si essencialmente um diversificado (ein Vielfaches), exterior, e condensar-se, a partir de ambos, passando à absoluta totalidade, de tal forma que, igualmente, um grande indivíduo universal exista enquanto espírito de um povo, o qual [é] absolutamente enquanto um Sendo nos indivíduos (das absolut als ein in den Individuen Seiendes), - os quais são suas singularidades, / seus órgãos; também, como, justamente nisso, contraposto a eles. (HEGEL, 1986, p. 187-188)

Uma vez que a essência da consciência é a unidade dialética de si mesma e de seu outro, isto é, de sua atividade e de sua passividade, a consciência que é espírito absoluto, espírito de um povo, põe sua atividade na mesma medida em que a põe suspensa como passividade. A unidade dos dois elementos da consciência é a unidade de sujeito e objeto da qual a filosofia do espírito parte enquanto não desdobrada, e para a qual ela retorna, mas agora na forma de um "espírito ético" enquanto autoconhecimento do espírito, uma apresentação real da ideia na unidade absoluta de universal e particular.

\section{Atividade consciente, passividade e "meio"}

O retorno do espírito enquanto conhecer absoluto e como espírito que se conhece a si mesmo é prefigurado na estrutura da consciência como meio (Mitte), isto é, na remissão constante, gradualmente enriquecida, da consciência individual à idealidade da consciência absoluta.

[...] ambos os diferenciados na consciência estão fora um do outro, eles se apartam. Sua unidade aparece, portanto, como um meio (als eine Mitte) entre eles, como a obra de ambos, como o terceiro, 
ao que eles se referem (worauf sie sich beziehen), no qual eles são um, mas como aquilo em que, do mesmo modo, ambos se diferenciam. (HEGEL, 1986, p. 191).

O Systementwurf de 1803/04 ainda opera num ambiente híbrido de uma teoria da consciência em meio a resquícios do método das potências, o que desemboca na compreensão das formas do espírito teórico e prático como potências (LIMA, 2006, p. 150). Para Hegel, a cada potência corresponde a organização da consciência segundo um meio (Mitte), ao qual se relacionam os opostos passividade e atividade, consciência e objeto: o meio, responsável pela mediação entre a idealidade e a realidade, por sua parte, também existe, de sorte que a consciência adquire, enquanto meio, uma existência diferente da oposição de idealidade e da realidade. Os meios aparecem assim como a unidade de opostos, mas também como sua diferença e, por conseguinte, como duplos (HEGEL, 1986, p. 191). Assim, a consciência ou o espírito são compreendidos por Hegel numa tríplice maneira: como meio dos contrapostos idealidade e realidade. No sentido em que revelam a diferença, os meios são ideais: a memória, o trabalho e a família, todos os elementos que denotam a subsistência de um embate entre a atividade e a passividade da consciência. Por outro lado, enquanto revelam a unidade, são ditos "[...] meios duradouros ou a existência universal da consciência", ou seja, língua (Sprache), instrumento (Werkzeug) e bem-da-família (Familiengut) (HEGEL, 1986, p. 191). A potência significa então o "ambiente" teórico ou prático formado pela duplicidade dos meios da consciência, de sorte que aqui a sucessão de potências não mais é pensada como respeitando um método exterior (LIMA, 2006, 2008b), mas como processo de desenvolvimento da consciência que permite que ela conheça progressivamente seus momentos essenciais.

E a organização da mesma [a consciência E.C.L] na realidade de seus momentos [é] uma organização de suas formas como meios. Enquanto absolutamente universal, simples, ela tem de se tornar para si igualmente o contrário de si mesma, atravessar a oposição, ou ser no produto sinteticamente contraposta. (HEGEL, 1986, p. 191).

É a organização das formas da consciência como meios que possibilita apresentar as potências da filosofia do absoluto como formas da consciência, o meio do aparecimento espiritual. "Ao conhecermos o desmembramento da consciência em sua totalidade, então nós tomamos conhecimento de como ela é para si como momento, em uma determinidade (wie es sich als Moment, in einer Bestimmtheit ist); e ela é enquanto uma determinidade, como uma em contraposto, sendo um meio" (HEGEL, 1986, p. 191). Linguagem, 
instrumento e bem-da-família se constituem, portanto, como formas da existência exterior da consciência como medium, isto é, formam o "ser" da consciência.

Eis por que se pode interpretar a formulação peculiar, dada por Hegel à teoria da consciência nesta fase, como uma tentativa de romper com o quadro geral de um mentalismo levado às últimas consequências por sua guinada transcendental, isto é, uma reação às inúmeras oposições conceituais em que incorre o idealismo kantiano-fichteano na tentativa de explicar as questões epistemológicas fundamentais acerca da "origem e da dependência causal do conhecimento" (HABERMAS, 1999, p. 193), oposições que desembocam na querela pós-kantiana acerca da "coisa em si". A resposta de Hegel às antinomias da autorreflexão consistiria, assim, em uma compreensão do desenvolvimento da consciência, a "[...] estrutura fundamental não desenvolvida do espírito" (WILDT, 1983, p. 329), segundo media que "estruturam previamente as potenciais relações entre sujeito e objeto." A compreensão hegeliana da consciência como medium se dirige contra a concepção mentalista de uma subjetividade exteriormente limitada e autossuficiente, a qual é, por isso, presa, segundo Habermas, de dualismos entre o interior e o exterior, ou entre o público e o privado. Aquela razão prática descentrada, depurada pela guinada transcendental do mentalismo, é liberada por Hegel dos limites autorreferentes da reflexão sobre si, o que significa que Hegel confere voz às relações entre sujeito e objeto já previamente estabelecidas antes que o próprio sujeito efetivo incorra em determinadas contraposições ao seu exterior.

\begin{abstract}
Hegel refuta a tese de que o sujeito cognoscente, falante e agente se encontra diante da tarefa de construir uma ponte sobre o abismo entre si e o outro separado dele. Um sujeito que está de antemão junto de seu outro não percebe nenhum déficit que exija compensação. Percepções e juízos se articulam em uma teia de conceitos previamente fechada lingüisticamente, ações se perfazem na esteira de práticas executadas. Um tal sujeito não pode estar junto a si mesmo sem estar junto ao outro. Esta experiência central não é somente cognitivamente relevante, ela é também a chave para os conceitos normativos hegelianos do amor, o estar-junto-a-si no outro (Bei-sich-selbst-sein im Anderen), e da liberdade, o estar-no-outro-junto-a-si (Im-Anderen-bei-sichselbst-Sein). (HABERMAS, 1999, p. 195).
\end{abstract}

Nesse contexto, com o conceito hegeliano de media, a pré-estruturação das relações sujeito-objeto antecipadoras da própria efetividade, enquanto experiência consciente, é a própria relação tradicional entre sujeito e objeto 
que é totalmente modificada: sujeito e objeto passam a somente existir em e através de suas relações.

\section{Meio e formação societária das capacidades prático-cognitivas}

Como se sabe, Habermas depreende dos esboços hegelianos de Jena uma orientação teórica fundada na irredutibilidade de linguagem, trabalho e interação, pela qual pretende vivificar a teoria materialista da sociedade. Entretanto, confere ao Hegel de 1803/04 também o papel de arauto do "[...] poderoso movimento de destranscendentalização do sujeito cognoscente", cujo ensejo fora certamente a própria filosofia do "último metafísico". Teria cabido a Hegel o mérito de ter iniciado o processo de recondução do sujeito transcendental kantiano à sua situação no espaço social e no tempo histórico. "Aquela primeira existência vinculada da consciência como meio é seu ser como linguagem, como instrumento e como os bens (das Gut); ou, como simples ser-um: memória, trabalho e família" (HEGEL, 1986, p. 193) Nesse contexto, o pontapé inicial do processo de destranscendentalização, operado por Hegel no quadro da "guinada transcendental" do mentalismo empreendida por Kant e Fichte, consiste na ruptura, através da introdução da linguagem, do trabalho e da interação como media pelos quais "[...] o espírito humano é impregnado e transformado" (HABERMAS, 1999, p. 186187) e que "estruturam previamente as relações que o sujeito cognoscente e agente estabelece com os objetos no mundo" (HABERMAS, 1999, p. 188), com um modelo cognitivo de autorreflexão que é determinante em toda tradição filiada a Descartes e que alcança Kant e Fichte.

Para o ponto de vista da consciência, que somente enxerga a oposição da consciência, ambos os lados da própria consciência aparecem em ambos os lados da oposição. A memória aparece do lado do que é consciente de si, já a linguagem, do outro lado; da mesma forma, o trabalho daquele lado, já o instrumento deste; igualmente família daquele, e os bens-de-família (Familiengut) deste lado. (HEGEL, 1986, p. 193).

Para Hegel, a atividade diferenciadora da consciência, pela qual ela se cinde em consciência e naquilo de que é consciente, é, em decorrência de sua própria "essência espiritual" enquanto igualdade dos lados, também o "ambiente" em que se torna possível a diferenciação: a unidade consciente de si como memória ou "acervo linguístico", trabalho ou "reprodução material" e família ou "relação ética ou intersubjetiva" são pré-articulados pela existência da consciência enquanto meio espiritual em que se formam, isto é, como "linguagem, instrumento e bens". 
Hegel enfatiza que tanto o ser-um de cada potência quanto a unidade existente do meio "são o absolutamente universal"; o medium é, entretanto, em cada caso, "universal como existente e como absolutamente existente, como contínuo (dauernd), como tendo existência universal" (HEGEL, 1986, p. 194). A linguagem, o instrumento e a relação ética articulam, portanto, enquanto existência "exterior e interior" da consciência como espírito, não apenas a "forma do objetivo", mas também a própria consciência singular contraposta a este objetivo e que, por seu próprio movimento, concebe-se como autoconsciência. "Ele é como ativo (er ist als Tätiges). Estes meios não são aquilo contra o qual ele [é] ativo: não contra a linguagem, instrumento e bens-de-família enquanto tais, e sim o meio (die Mitte), ou como é denominado, o termo médio (das Mittel) através do qual e por meio do qual ele é ativo contra um outro" (HEGEL, 1986, p. 193). É a própria ambivalência do medium enquanto aquilo que estrutura previamente a experiência da consciência e aquilo que a permite estruturá-la que cria a dualidade entre atividade e passividade da consciência com relação ao meio.

Ele somente é ativo através do outro lado do meio: memória, trabalho e família [...] o indivíduo se encontra, enquanto singular, muito mais sob a dominação deles do que eles sob a sua. (HEGEL, 1986, p. 193).

Trata-se aqui do estatuto supraindividual, individualmente formativo, dos media, o qual é certamente mais visível no caso da relação ética, mas vale também para os outros meios, na medida em que forjam a espontaneidade da autoconsciência individual. Se a consciência de um sujeito singular é relação de contraposição entre um sujeito empírico e seu objeto, os media, enquanto nexos espirituais no âmbito da consciência, são os vínculos unificadores da cisão, abrangem e unificam os termos, de tal modo que sempre ultrapassam a consciência dos sujeitos singulares (HABERMAS, 1999, p. 201). Eis porque essa dominação é somente aparente e, desse modo, "[...] não há, de forma nenhuma, relação de dominação do indivíduo ou contra o indivíduo, e sim o indivíduo é somente um lado formal da oposição" (HEGEL, 1986, p. 193-194). Enquanto os media linguagem e trabalho são os termos médios nos quais a contraposição entre sujeito e objeto, entre autoconsciência e consciência se estabelece, a interação, isto é, a relação entre duas consciências forma a existência social efetiva da consciência ou do espírito, "[...] o mundo da vida compartilhado intersubjetivamente" (HABERMAS, 1999, p. 201), conferindo subsistência aos media que constituem a consciência teórica e prática dos sujeitos singulares, a sua capacidade de conhecer e de dominar a natureza. Também nesse sentido o desenvolvimento da consciência enquanto sucessão de media 
faz a consciência singular ou empírica apontar para a consciência absoluta, sua realidade mais adequada (WILDT, 1983, p. 333).

\title{
Linguagem e Razão teórica
}

A primeira unidade ideal-real, delimitada pela oposição linguagem/ memória, é compreendida como processo teórico. "A primeira forma da existência da consciência é a consciência em geral, o conceito do espírito, tal como ele, enquanto este conceito ou como consciência, se torna a totalidade, sua existência puramente teórica" (HEGEL, 1986, p. 195). O sentido geral da compreensão hegeliana da linguagem como medium reside em que, por meio dela, a consciência singular é previamente articulada em conexão com todos os objetos "exteriores", o que leva justamente à suspensão da contraposição entre o sujeito que representa e o objeto representado. Para Hegel, nesse conceito de espírito,

\begin{abstract}
[...] seus momentos contrapostos são da mesma forma conceitos, universais em geral e, por isso, não se relacionam um ao outro enquanto absolutamente contrapostos, mas antes se relacionam formalmente um ao outro no elemento simples da consciência, [não como] intactos em seu ser-para-si, e sim se suspendendo um em face do outro em sua forma, e fora da mesma permanecendo ainda para si. (HEGEL, 1986, p. 195).
\end{abstract}

Em outras palavras, a consciência cognoscente é como que forjada na antecipação "linguística" da suspensão de conceito e objeto, de maneira que a capacidade cognitiva do sujeito singular se exerce, na medida em que o arcabouço das experiências possíveis é previamente articulado linguisticamente, quer como intuição, quer como conceito, sempre apoiada no estofo linguístico anterior à própria contraposição.

\begin{abstract}
A linguagem é, segundo sua essência, existente para si mesma, natureza posta idealmente, e ela é como que mera forma, ela é um mero falar, uma exterioridade. Ela não é um produzir, mas a simples forma do tornar-exterior (die bloße Form des Äußerlichemachens) o que já foi produzido, como isto tem de ser falado, o formal da pura atividade, o devir imediato do ser-interior em seu contrário (das unmittelbare Werden des Innerlichsein zu seinem Gegenteile), em um exterior. (HEGEL, 1986, p. 226).
\end{abstract}

A existência do medium linguístico é o protótipo do mundo conhecido, a idealidade da natureza: a "forma" da cognição é imediatamente, pela 
linguagem, a exterioridade de que fala. A linguagem é, portanto, o meio ou produto da contraposição interior/exterior. "A consciência existe primeiro como memória e seu produto, a linguagem" (HEGEL, 1986, p. 195). Enquanto nexo unitário do medium linguístico, a memória forma, por sua vez, o arcabouço linguístico em que toda a experiência cognitiva está préestruturada: trata-se também, com efeito, da cognição em sua existência perene e, por isso, excede, como tal, a singularidade de um sujeito cognoscente. "Somente em um povo existe aquilo - já posto como suspenso, existente como consciência universal, ideal - que a memória, o tornar-se linguagem (das Werden zur Sprache) torna primeiramente ideal" (HEGEL, 1986, p. 226). Com a memória, a atividade cognitiva do sujeito singular aponta já para a sua plena efetivação e para sua existência contínua, no horizonte histórico da existência de um povo, de uma comunidade de indivíduos que compartilham uma língua e uma tradição.

\begin{abstract}
A linguagem é somente como linguagem de um povo ... Somente como obra de um povo a linguagem é a existência ideal do espírito, na qual ele exprime o que ele é segundo sua essência e em seu ser. Ela é um universal, em si reconhecido, que ecoa da mesma maneira na consciência de todos. Cada consciência falante se torna nela uma outra consciência. Da mesma maneira, segundo seu conteúdo, somente num povo ela se torna linguagem verdadeira, exprimir o que cada um quer dizer. (HEGEL, 1986, p. 226-227).
\end{abstract}

Por outro lado, ainda no nível da potência teórica da língua e da memória, a consciência "[...] se torna, através do entendimento, enquanto o ser do conceito determinado, conceito absoluto simples, reflexão absoluta em si, vacuidade da capacidade formal da absoluta abstração. E a relação da oposição se torna um suprimir de diferentes que em si [estão] um contra o outro" (HEGEL, 1986, p. 195). Portanto, o resultado do processo teórico é alcançado depois do entendimento, é o conceito absoluto simples, a absoluta reflexão (a)dentro de si mesma, a vacuidade da faculdade formal da absoluta abstração, a qual não é decerto apenas a pura autoconsciência do idealismo kantiano-fichteano, não um ponto de partida pressuposto como fato, mas o resultado do desenvolvimento e autossuspensão das oposições examinadas no medium linguagem. "Ao tomar-lhes sua forma, a consciência determina a oposição de um lado como forma absolutamente sendo-para-si, reflexão absoluta em si mesma, absoluta vacuidade do conceito, e do outro lado como matéria absoluta" (HEGEL, 1986, p. 195). Ao término da potência definida pelo meio teórico da língua e da memória, a consciência não é ainda a unidade de universalidade e singularidade, mas a unidade pontual vazia da individualidade, à qual se contrapõe a totalidade de determinidades enquanto 
realidade estranha. O resultado da potência teórica é a unidade da unidade do conceito e da multiplicidade de determinidades, ou a razão formal, a qual se contrapõe novamente à singularidade, ao pôr sua própria como suspensa.

Eis por que, no nível da potência teórica, a linguagem ainda não se refere à comunicação propriamente dita de sujeitos agentes e que coexistem, mas se vincula ainda à simbolização linguística a que recorre o indivíduo apartado em sua confrontação com a natureza. Se a memória forma o estofo interior da utilização de símbolos, a linguagem como tal é a primeira categoria pela qual o espírito é pensado como medium, como elemento interior e exterior, o qual ultrapassa assim a reflexão da autoconsciência solitária. Entretanto, enquanto "reconstruída [...] em um povo", a linguagem se torna um aniquilar do exterior que é, ele mesmo, uma exterioridade,

\begin{abstract}
[...] o qual tem de ser aniquilado, suspenso, a fim de se tornar linguagem designativa (um zur bedeutenden Sprache zu werden), tornar-se aquilo o que ela é em si, segundo seu conceito. Portanto, ela é no povo como um outro algo morto que não ela mesma, tornando-se totalidade ao ser superada enquanto um exterior e ao chegar a seu conceito (zu ihrem Begriff wird). (HEGEL, 1986, p. 227).
\end{abstract}

\title{
Formação societária e Individualização
}

O resultado acumulado no desenvolvimento da consciência é que, na potência do instrumento, a consciência compreende que não é independente daquilo que ela quer negar, mas que somente tem a consciência de si mesma no outro. Habermas sustenta que os processos das potências teórica e prática, baseados na noção de medium, deixam ainda sem explicação, ao se deterem na perspectiva da consciência singular que se contrapõe à natureza, o sentido mais profundo de objetividade vinculado àquela noção, na medida em que se referem ao que ultrapassa a subjetividade da contraposição. A verdade é que ambos os media, em seus momentos ideais (HABERMAS, 1999, p. 204), memória e trabalho, remetem a unidades que excedem a mera contraposição singular e encontram sua realidade efetiva no estofo linguístico usado por uma cultura para a interpretação do mundo e no aproveitamento social da racionalidade instrumental e técnica na reprodução material de uma comunidade.

A tese de Hegel é que ambos os media somente encontram sua realidade perene e acabada no espírito do povo. Contudo, a constituição do espírito, cuja objetividade excede a mera subjetividade singular, passa pelo 
compartilhamento intersubjetivo de práticas comuns ligadas à vida e à tradição comunitária. É nesse sentido que a vida afetiva no seio da família vem complementar o desenvolvimento dos media.

Na Filosofia do Espírito de 1803/04, a discussão sobre a potência da família marca a passagem da "teoria da consciência", forma prototípica do espírito subjetivo, para a filosofia da eticidade, que contém a prefiguração do espírito objetivo. É na relação interativa própria à potência da família que se realiza o que a consciência pôde vislumbrar, na esfera do instrumento, a saber: que ela tem sua consciência de si mesma somente no seu outro, ou seja, é esta unidade da relação passiva e ativa ao outro somente na interação dos indivíduos que se corporifica no amor, no casamento e na educação dos filhos. Com tal tese, Hegel faz mais uma vez do ponto de partida de sua teoria do desenvolvimento da eticidade um nexo societário que responde por uma relação de intersubjetividade inclusiva e participativa, substancialmente contraposta à intersubjetividade excludente das relações de direito privado. Analisado sob a perspectiva de sua relação com a luta por reconhecimento, que se instaura com a plena formação das individualidades no solo ético familiar, esse elemento de uma intuição imediata de si no outro se constitui, revelando o extremo potencial normativo da tese hegeliana da gênese conceitual da sociedade civil como processo de dissolução ética da família, como condição de uma individualização socialmente instituída e a ser juridicamente institucionalizada. Entretanto, sua deficiência se revelará ainda na permanência da unidade de ser-para-si e objetividade, atividade e passividade nos limites da consciência da singularidade. Nesses termos, a unidade da consciência na interação familiar mostra seu caráter excludente correspondente à atividade negativa e excludente da consciência prática singular.

Este meio, no qual eles se conhecem como um, como tendo suspendido sua oposição, e no qual eles justamente por isso novamente se contrapõem, é como [meio] sendo-para-si. Este lado do meio, no qual eles se conhecem como Uno e como suspensos, é necessariamente uma consciência, pois eles somente são um enquanto consciência: é a criança, na qual eles se conhecem como em uma única consciência (in welchem sie sich als in Einem Bewußtsein) enquanto Uno, e justamente nisso como suspensos; e eles vêem (anschauen) nela este seu ser-suspenso (Aufgehobenwerden). Eles se conhecem nela [...] como unidade que veio-a-ser (als gewordne Einheit). (HEGEL, 1986, p. 213).

Se o amor e o casamento formam o meio termo entre os indivíduos, é somente na criança que esse "termo médio" se revela, enquanto consciência que é unidade das consciências, em seu caráter genuíno, a existência plena 
do elemento consciente-de-si na alteridade dos pais, existência na qual eles mesmos se veem, ao resgatar sua oposição extrema de termo separado. A tese geral de Hegel a respeito da duplicidade do medium, compreendida no horizonte de sua exposição da potência da família, é considerada como intuição dos pais de seu ser-suspenso na criança enquanto existência objetiva de sua unidade, o que conduz às suas interessantes colocações sobre a educação e seu papel como nexo formativo da individualidade. "Essa unidade que veio-a-ser é ela mesma uma consciência e, na verdade, uma consciência na qual o ser-suspenso dos pais se intui (sich anschaut), ou seja, ela é uma consciência na qual vem a ser a consciência dos pais. Em outras palavras, os pais têm de educá-la (erziehen)" (HEGEL, 1986, p. 213).

A tese de que os pais veem na criança sua própria suspensão, pelo que a formam e educam, a fim de elevá-la ao nível de sua própria consciência, "[...] produzindo sua própria morte", é extremamente importante para uma apreciação, em termos de uma teoria dos processos de individualização e socialização, da teoria hegeliana da dissolução ética da família, bem como para a passagem à sociedade civil - que, mesmo no sistema maduro, pode ser ainda considerada como a permanente reposição de uma incessante luta por reconhecimento de indivíduos emergentes do solo afetivo da família. "O processo da individualidade é um configurar (Gestalten), e aquele que aqui consome em si a figura que vem-a-ser é a individualidade que vem-a-ser" (HEGEL, 1986, p. 213). Entretanto, deve ser compreendida no sentido em que a criança se forma, por sua vez, a partir de uma "objetividade consciente" que é a própria consciência dos pais, dela se nutrindo como condição de sua plena individualização.

Por conseguinte, a tese de que os pais produzem seu colapso, na medida em que educam a criança, tem sua compreensão orientada pela função individualizante que Hegel atribui ao nexo intersubjetivo da vida afetiva da família: um ambiente intersubjetivo que se caracteriza, enquanto elemento formador da individualidade, por seu papel inclusivo e participativo. Hegel parece então fundamentar a compreensão segundo a qual a formação de consciências singulares independentes depende de nexos sociais prévios à sociedade civil e que se compõem de elementos participativos na formação da individualidade.

Ao educá-la, eles põem nela a consciência deles que veio-a-ser (ihr gewordenes Bewußtsein) nela, e produzem sua [própria] morte ao vivificá-la até a consciência (es zum Bewußtsein beleben), com o que a consciência dos pais realiza sua reflexão em si mesma, a vacuidade da singularidade absoluta e, enquanto consciência que veio-a-ser, torna-se natureza inorgânica, a cuja totalidade o ser humano enquanto criança se eleva. (HEGEL, 1986, p. 213). 
Uma vez que os filhos são considerados a objetivação do saber-se no outro, a existência desse mesmo saber como consciência na qual os pais se veem a si mesmos enquanto gênero humano, a relação entre pais e filhos, especialmente a formação das consciências pela educação, é compreendida como o necessário "aprofundamento" da relação de conhecer-se a si mesmo no outro que estrutura a relação afetiva, uma experiência de "[...] vacuidade da singularidade absoluta", de descentramento da perspectiva egocêntrica "no interior do quadro familiar de expectativas recíprocas e normativas de comportamento" (HABERMAS, 1999, p. 205). Para a consciência em formação,

[... ] a consciência dos pais é sua matéria, às custas da qual ela se forma. Eles são para ela um obscuro e desconhecido pressentir (Ahnden) de si mesma, eles suspendem seu simples e ensimesmado ser-dentro-de-si (sein einfaches und gedrungenes Insichsein). O que eles dão a ela, eles o perdem; nela eles falecem, pois o que eles dão a ela é sua própria / consciência. (HEGEL, 1986, p. 213-214).

Na relação de formação e interação educativa no interior da família, pela qual a criança se revela o "meio consciente" da intuição recíproca, o descentramento significa, para os pais, uma contraposição aos filhos na forma de uma subordinação da singularidade própria à consciência que se constitui, a experiência propriamente ética de descentramento de seu eu "ensimesmado". "Nesta perspectiva, os parceiros se reconhecem, ao mesmo tempo, como membros de uma comunidade particular, como pertencentes a uma família, na qual se cristalizam direitos e deveres concernentes a funções da socialização ("educação da criança") e da reprodução material ("bem-dafamília")" (HABERMAS, 1999, p. 205). Desse modo, do ponto de vista da "existência ética" dos indivíduos, ambos os lados se põem em um processo recíproco de formação, cujo produto é uma consciência essencialmente supraindividual. "Com isso, na família, a totalidade da consciência é o mesmo que algo que vem-a-ser para si mesmo. O indivíduo / vê a si mesmo no outro. O outro é o mesmo todo da consciência, e ela tem sua consciência no outro, no produzido" (HEGEL, 1986, p. 214-215). Por conseguinte, na interação familiar, é a própria consciência que se ergue, para Hegel, à sua totalidade própria, como uma consciência que devém para si mesma. "A consciência se torna uma tal consciência que põe em si uma outra consciência. $\mathrm{Na}$ educação se suprime a unidade sem-consciência (die bewußtlose Einheit), esta [unidade] se desmembra em si, ela se torna consciência formada (wird zum gebildeten Bewußtsein)" (HEGEL, 1986, p. 213). 
Individualização como formação de capacidades prático-teóricas

Se, por um lado, sob a perspectiva dos pais, a educação deixa ver, em uma antecipação da existência ética dos indivíduos, o descentramento ético da consciência singular; por outro lado, a perspectiva da criança, a qual coincide com a formação da consciência para a totalidade que se tornará absolutamente excludente na luta por reconhecimento, deixa ver o papel sistemático assumido pela potência da família em relação às potências anteriores.

\begin{abstract}
Até aqui, para a consciência, era o outro, enquanto ela mesma, contraposição absoluta, um puramente outro; aqui a consciência se tornou para si mesma um outro: para os pais, a criança; para a criança, os pais. E a educação da criança consiste em que a consciência posta para ela como uma outra que não ela se torne sua própria [consciência]. (HEGEL, 1986, p. 213).
\end{abstract}

Eis por que Hegel pretende que o processo de formação da criança seja, em face da idealidade teórica indiferente da razão formal e da "singularização absoluta" da consciência que se eleva à independência no "desejo refreado", a unidade da consciência teórica e prática. "Para a consciência ativa que até aqui estava na oposição, é superada a própria oposição, ao ser o outro lado, posto até aqui como o lado não consciente, ele mesmo uma consciência... a consciência se produz para si mesma como identidade do interior e do exterior" (HEGEL, 1986, p. 214). Como com isso, segundo Hegel, a consciência alcança a efetivação imediata de sua estrutura essencial, de ser imediatamente o contrário de si mesma, a consciência atinge, na família, sua totalidade. A totalidade da família é a efetivação apenas imediata da estrutura da consciência justamente porque não se trata ainda com ela de uma totalidade extensiva, mas uma totalidade apenas intensiva e particular. O reconhecimento é o movimento pelo qual essa totalidade intensiva, alcançada como ponto culminante do processo prático, se amplia na forma do autoconhecimento em toda outra totalidade, o que representa o desenvolvimento da aptidão fundamental para a vida ética.

Bastante ilustrativa é também a maneira como a formação da consciência na educação se conecta com os tópicos desenvolvidos na potência teórica, especialmente com a articulação linguística prévia da cognição. Aparentemente, os temas parecem sem ligação, na medida em que na "potência teórica, ela se tornou para nós uma [consciência] absolutamente singular na racionalidade formal" (HEGEL, 1986, p. 213), enquanto, na formação, "[...] a consciência é [...] o devir de uma outra consciência nela" (HEGEL, 1986, p. 214). Entretanto, esclarece Hegel, na formação da consciência é a própria relação da mesma com o mundo enquanto cognição que se modifica, 
já que, a rigor, não há aqui simplesmente um meio entre a consciência e seu outro, mas antes a alteridade já é igualmente consciência. "O mundo não chega até esta consciência enquanto um devir, como até agora, na forma absoluta de um exterior (eines Äußern), mas trespassado pela forma da consciência" (HEGEL, 1986, p. 214). Essa pré-articulação do mundo pela própria consciência dos pais tem um significado interessante, pois, na educação, já foi decididamente rompido o âmbito da cognição solitária, e a consciência em formação se nutre, na verdade, de um saber previamente articulado em um duplo sentido. Em um sentido próximo, porque "[...] a natureza inorgânica dela é o saber (Wissen) dos pais, o mundo é de antemão um [mundo] preparado, e a forma da idealidade é o que chega até a criança" (HEGEL, 1986, p. 214). Em um sentido remoto, pois o "meio" linguagem revelou a articulação linguística prévia da cognição.

\begin{abstract}
A formação (Bildung) do mundo em linguagem está em si presente (ist an sich vorhanden). Tal como o devir da razão e do entendimento, ela recai na educação, ela existe para a consciência que devém (für das werdende Bewußtsein) enquanto mundo ideal, enquanto sua natureza inorgânica; e ela não tem de se desvencilhar desta maneira da natureza, mas sim de encontrar para a idealidade da mesma a realidade, de procurar para a linguagem o significado, que está no ser. Este é da mesma maneira para a mesma [consciência], ele permanece somente como que a / atividade formal do relacionar dos mesmos, que já são, uns aos outros. (HEGEL, 1986, p. 226-227).
\end{abstract}

Portanto, é na educação e para a consciência que vem-a-ser que se revela verdadeiramente a pré-estruturação linguística da experiência cognitiva. Em um sentido ontogenético, a abstração da potência teórica, razão e entendimento são formados concretamente, isto é, à parte do processo "abstrato" descrito na potência teórica, sem a necessidade de que o sujeito cognoscente rompa sua relação de imersão com o mundo circundante, justamente porque seu mundo circundante já é "idealizado" e estruturado linguisticamente pela consciência dos formadores. A concretude da atitude cognitiva em um sentido ontogenético, reduzida a uma "atividade quase-formal de relacionar", reside apenas no restabelecimento da referência, previamente estruturada, entre linguagem e objeto, entre idealidade e realidade. "Vindo o mundo, enquanto este mundo ideal, até a criança, então é a tarefa desta consciência encontrar o significado, a realidade deste ideal, como o ideal existe. Ela tem de realizar este ideal" (HEGEL, 1986, p. 214). A "relação da consciência" se inverte, pois antes consciência singular e mundo se contrapunham como idealidade e realidade, enquanto " [...] aqui a consciência é o singular, e o outro lado de sua oposição é o ideal, um mundo, tal como ele é na consciência" (HEGEL, 1986, p. 214). A consciência 
ativa que fecha a potência prática exercia-se como "atividade absolutamente contraposta" (HEGEL, 1986, p. 214), ao passo que, para a criança enquanto consciência que vem-a-ser, dissolve-se a contradição entre o mundo real e o mundo ideal, "ao pôr idealmente o lado real, para ela não consciente, e realizar o lado consciente, o [lado] ideal dos pais [...] Ela unifica ambos e é, primeiramente, uma consciência que veio-a-ser ela mesma. Ela supera da mesma forma o exterior, na medida em que supera a interioridade, a idealidade: ambos existem para ela como um exterior" (HEGEL, 1986, p. 214).

LIMA, E. C. Language and Formation in Hegel's Theory of Consciousness. Trans/Form/ Ação, (Marília); v.34, n.1, 2011, p. 67-86.

ABSTRACT: This paper aims at presenting the connection between formative processes and the linguistic structure of cognition in Hegel's theory of consciousness, developed in the Philosophy of Spirit (1803/04). First I consider the general aspects of Hegel's above-mentioned theory of consciousness. Then I attempt to interpret this theory as related to formative processes of practicalcognitive capacities. After this the paper focuses on the relation of language and theoretical reason, as it is presented by Hegel in his Philosophy of Spirit. Finally, I analyze the linguistic structuration of cognition within the context of social processes of consciousness development.

KEYWORDS: Education. Language. Consciousness. Cognition. G. W. F. Hegel.

\section{Referências}

BAUM, M. Die Entstehung der Hegelschen Dialektik. Bonn: Bouvier, 1989.

GILBERT, G. Critique et dialectique: l'itinéraire de Hegel à Iéna (1801-1805). Bruxelles: Facultés Universitaires Saint-Louis, 1982.

HABERMAS, J. Arbeit und Interaktion. Bemerkungen zu Hegels Jenenser "Philosophie des Geites". In: GÖHLER, G. Frühe politische Systeme. Frankfurt am Main: Ullstein, 1974. p. 794-815.

Individuierung durch Vergesellschaftung. In: HABERMAS, J. Nachmetaphysisches Denken. Frankfurt am Main: Suhrkamp, 1988. p. 187-241.

Wege der Detranzendentalisierung: Von Kant zu Hegel und züruck. HABERMAS, J. Wahrheit und Rechtfertigung: philosophische Aufsätze, Frankfurt am Main: Suhrkamp, 1999. p. 197-228.

HARRIS, H. S. The concept of recognition in Hegel's Jena Manuscripts. HegelStudien, Frankfurt, v. 20, p. 229-248, 1980. 
HEGEL, G. W. F. Werke in 20 Bände. Frankfurt am Main: Suhrkamp, 1970.

Jenaer Systementwürfe. I. Hamburg: Felix Meiner, 1986.

HONNETH, A. Kampf um Anerkennung. Zur moralischen Grammatik sozialer Konflikte. Frankfurt am Main: Suhrkamp, 1992.

HORSTMANN, R. Probleme der Wandlung in Hegels Jenaer Systemkonzeption. Philosophische Rundschau, Tübingen, v. 19, p. 87-118, 1973.

KIMMERLE, H. Das Problem der Abgeschlossenheit des Denkens. Hegels System der Philosophie in den Jahren 1800-1804. Bonn: H. Bouvier, 1970.

LIMA, E. C. Direito e intersubjetividade: eticidade moderna em Hegel e o conceito fichteano de reconhecimento. 2006. 293 f. Tese (Doutorado em Filosofia) Universidade Estadual de Campinas, Campinas, 2006a.

Eticidade e intersubjetividade: notas acerca da influência da filosofia social de Fichte sobre Hegel. In: BAVARESCO, A.; SILVA, M. M. (Org.). Filosofia, reconhecimento e direito. Pelotas: Ed. Universidade de Pelotas, 2006b. p. 13-65.

Gênese do espírito ético na Filosofia do Espírito de Jena. Cadernos de Ética e Filosofia Política, São Paulo, v. 10, p. 79-102, 2007a.

. Intersubjetividade, direito e educação: sobre a leitura hegeliana do Direito Natural de Fichte. Dois Pontos, Curitiba, v. 2, p. 11-54, 2007b.

Formação social da consciência jurídica: observações sobre a conexão entre intersubjetividade e normatividade em Kant e Fichte. Princípios, Natal, v. 14, p. 221-252, 2008a.

Movimento da consciência e eticidade: para uma localização do Systementwurf 1803/04. Revista de Filosofia, Curitiba, v. 20, p. 151-182, 2008b.

Momentos da Articulação Comunitária da Vereinigung: dialética e sociedade no jovem Hegel. Dissertatio, Pelotas, v. 26, p. 61-110, 2008c.

Resenha de sofrimento de indeterminação, de Axel Honneth. Cadernos de Filosofia Alemã, São Paulo, v. 11, p. 127-140, 2008d.

O Fragmento 22 dos Jenaer Sytementwürfe (1803/04): apresentação e tradução. Revista Eletrônica de Estudos Hegelianos, Recife, v. 5, p. 75-98, 2008e.

MEIST, K. Hegels Systemkonzeption in der frühen Jenaerzeit, In: DÜSING, K. Hegel

in Jena. Bonn: Bouvier, 1980. p. 59-79.

Einleitung. In: G. W. F. Hegel, System der Sittlichkeit [Critik des Fichteschen Naturrechts]. Hamburg: Felix Meiner, 2002. p. 1-57

PATTEN, A. Hegel's idea of freedom. New York: Oxforf University Press, 1999. 
PINKARD, T. Hegel's phenomenology: the sociality of reason. Cambridge: Cambridge University Press, 1994.

SCHNÄDELBACH, H. Hegels praktische Philosophie: Ein Kommentar der Texte in der Reihenfolge ihrer Entstehung. Frankfurt am Main: Suhrkamp, 2000.

SIEP, L. Anerkennung als Prinzip der praktischen Philosophie. Freiburg/München: Alber, 1979.

Der Freiheitsbegriff der praktischen Philosophie Hegels in Jena. In: SIEP, L. Praktische Philosophie im deutschen Idealismus. Frankfurt am Main: Suhrkamp, 1992. p. 35-55.

Die Bewegung des Anerkennens in der Phänomenologie des Geistes. In: KÖHLER, D. G.W.F Hegel, Phänomenologie des Geistes. Berlin: Akademische Verlag, 2006. p. 233-257.

Der Weg der Phänomenologie des Geistes. Ein einführender Kommentar zu Hegels "Differenzschrift" und "Phänomenologie des Geistes". Frankfurt am Main: Suhrkamp, 2000

Selbstverwirklichung, Anerkennung und politische Existenz. Zur Aktualität der politischen Philosophie Hegels. In: SCHMÜCKER, R. Gerechtigkeit und Politik. Philosophische Perspektiven. Berlin: Akademie Verlag, 2004. p. 4156 .

WILDT, A. Autonomie und Anerkennung. Hegels Moralitätskritik im Lichte seiner Fichte-Rezeption. Stuttgart: Klett-Cotta, 1983.

WILLIAMS, R. Recognition: Hegel and Fichte on the other. Albany: University of New York Press, 1992. 1997.

Hegel 's ethics of recognition. Los Angeles: University of California Press, 